Brit. F. vener. Dis. (1971) 47, 95

\title{
Re-appraising the effect on incubating syphilis of treatment for gonorrhoea
}

\author{
KEVIN R. WOODCOCK \\ St Mary's Hospital, Paddington, London, W.2
}

Reference to the literature before 1950 reminds us that, in the early days of penicillin therapy for gonorrhoea, a major subject of concern was the possible masking of syphilitic infection. The usual dose employed was 100,000 to 150,000 units of penicillin, and it was very soon shown by Mahoney, Arnold, and Harris (1943) that 100,000 units would produce rapid but temporary healing of primary syphilitic lesions. Many opinions were expressed about the length of follow-up necessary to protect against the risk that masked syphilis might pass unnoticed. Canizares (1944) advised that blood tests should be continued at intervals for 1 year 'and preferably longer'. Lydon and Cowe (1945) thought that surveillance for 2 years was necessary; Allan (1946) recommended blood tests for 12 months. Magnuson and Eagle (1945), basing their views on rabbit experiments, considered a minimum follow-up of 4 months to be essential. Cronin (1947), in a review of published cases, concluded that there was no evidence that penicillin in doses up to 150,000 units delayed the onset of syphilis beyond 3 months. A note of caution was sounded by Leeming (1947), who pointed out that the total number of cases of dual infection published was less than one hundred; he felt that negative evidence from so small a number of cases should not be so readily accepted, but 2 years later MacFarlane (1950), on the strength of a further 36 cases, restated the views of Cronin. Bauer (1949), in a follow-up of discharged American military personnel previously treated with penicillin for gonorrhoea, failed to show any significant amount of concealed syphilis. Willcox (1950) found some evidence from national statistics that simultaneously-acquired syphilis was being cured, in the incubation period, by the treatment of gonorrhoea.

There the matter seems to have rested, with most venereologists accepting that a 90-day follow-up period is adequate and many arguing that even this is unnecessary because there is little reason why, once

Received for publication August 5, 1970 the patient is cured of gonorrhoea, he should not take his chance on the diagnosis of syphilis along with those patients who caught syphilis uncomplicated by gonorrhoea.

\section{Justification for re-appraisal}

Nevertheless, there are at least two good reasons for reconsidering the problem of dual infections with gonorrhoea and syphilis:

(1) When the 'textbook' facts were being established, the average dose of penicillin used in the treatment of gonorrhoea was 0.15 mega unit or less. The minimum dose used today is eight times as large, and doses twenty to thirty times as large are not uncommon. Also, the penicillin used today is of a better quality. It therefore seems at least possible that the treatment of gonorrhoea may now be having a different effect on syphilis from that exerted in 1950.

(2) A knowledge of the effect of various doses and types of penicillin on incubating syphilis may promote a better control of syphilis throughout the world. In addition, the possibility arises that eventually penicillin will no longer be used in the treatment of gonorrhoea; the likely effects of this on the future incidence of syphilis would be best considered in advance.

\section{Difficulties involved}

That the problem has not been resolved more than 25 years after it first arose suggests that finding the answer may not be easy. The four major difficulties in studying the effect of gonorrhoea treatment on syphilis are:

(1) The relatively low incidence of syphilis and the fact that dual infections are not classified separately, at least in Great Britain.

In 1968 the total of new cases of gonorrhoea reported in England and Wales was 44,962, while there were only 3,741 cases of syphilis reported. Of the syphilis cases, more than half were judged to have been present for more than one year, only 
1,826 being diagnosed as early syphilis (primary, secondary, or latent in the first year of infection). This makes the ratio of early syphilis to gonorrhoea about 1:23 cases. The proportion of combined infections is not recorded.

(2) The poor follow-up rate on cured gonorrhoea cases.

At the St. Mary's Hospital clinic the 90-day follow-up rate is often as little as 5 per cent. and more than half of those followed for 90 days re-attend only because they develop further symptoms.

(3) The possibility that syphilis developing subsequent to the treatment of gonorrhoea may also have been caught subsequently.

Many venereologists no longer even recommend a 3-month abstinence from sexual intercourse because of the rarity with which such advice is followed.

(4) Total ignorance of the actual incidence of incubating syphilis in patients with gonorrhoea.

This makes it difficult to assess what happens to such infections when the gonorrhoea is treated.

\section{SERIES I: 2,992 MALE CASES OF GONORRHOEA}

An initial approach to the problem was made by considering the 2,992 male cases of gonorrhoea diagnosed at the St. Mary's Hospital clinic in 1968. The routine treatment in the majority of these cases was a single injection of 1.2 mega units procaine penicillin. From the proportions occurring nationally it might be expected that 135 cases of early syphilis would also be seen at this clinic. In fact 181 cases were diagnosed in that year, a figure 30 per cent. above the national average. Analysis of the case histories of the patients with gonorrhoea, however, revealed only 38 cases of early syphilis, thirty diagnosed concurrently and eight in the subsequent 6 months. The thirty ( 83.3 per cent.) diagnosed concurrently were treated before the effect of the gonorrhoea treatment could be judged.

Fig. 1 shows the proportions of cases of primary, secondary, and early latent syphilis. Only two cases (119 and 198 in Table I) occurred in the first 90 days, compared with six cases in the second 3 months after treatment. This difference between the two periods can be accounted for by the fact that any infection that had been present long enough to become secondary or latent in the first 90 days would have been likely to have been diagnosed from the examination and serological tests when the patient was first seen. Hence the relatively large number of cases occurring concurrently, the gonorrhoea providing a net to catch cases of syphilis acquired over a

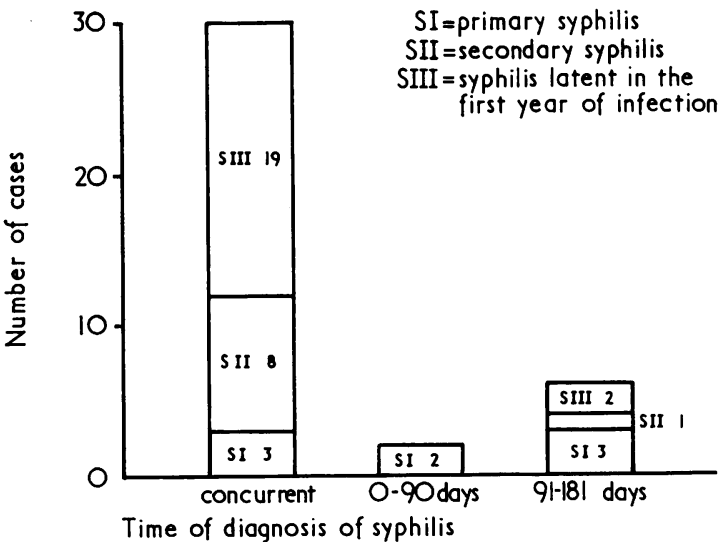

FI G. 1 Cases of early syphilis diagnosed, concurrently and during the subsequent 6 months, in 2,992 cases of gonorrhoea in men

much longer period. Yet it must be considered interesting, in a purely negative sense, that, out of nearly 3,000 cases of gonorrhoea, only two patients were known to have developed evidence of syphilis in the 90-day follow-up period, an incidence of 0.06 per cent.

When it was embarked upon, the aforementioned review of the gonorrhoea patients was all that was intended. When it was completed two points emerged:

(1) That subsequent infection with gonorrhoea provides a useful service to some patients in allowing a previous syphilitic infection to be diagnosed. To abandon prolonged follow-up tests for syphilis might, therefore, put at a relative disadvantage the less promiscuous patients who do not subsequently develop any new infection to bring them again under surveillance.

(2) That the difficulty in obtaining sufficient cases of dual infection for study is even greater than had been anticipated.

\section{SERIES II: 281 MALE CASES OF EARLY SYPHILIS} (a) Introduction and general statistics

The second approach, in an attempt to overcome the problem of numbers, was to consider the retrospective history of gonorrhoea in the previous 12 months in a series of male patients with early syphilis. To this end an analysis was made of all the patients attending this clinic with early syphilis between January 1, 1968, and June 30,1969 - a total of 281 cases. This series included all those patients with dual infection already discovered, and in addition certain patients whose gonorrhoea occurred in 1967 or the early months of 1969 , and those whose gonorrhoea had been treated elsewhere. A 12-month 
period was chosen, not because it was thought likely that the treatment of gonorrhoea might influence the incidence of syphilis for that long-although that is, of course, a possibility-but to provide some indication of the incidence of gonorrhoea and syphilis in the same patients, uninfluenced by the 'gonorrhoea net'.

The results are presented in Figs 2, 3, and 4, and Table I summarizes the information available in the case of those patients whose syphilis appeared

TABLE I Summary of 14 male patients known to have developed syphilis within 6 months of treatment for gonorrhoea

\begin{tabular}{|c|c|c|c|c|c|c|c|c|c|c|c|}
\hline \multirow[t]{2}{*}{$\begin{array}{l}\text { Patient } \\
\text { no. }\end{array}$} & \multirow[t]{2}{*}{$\begin{array}{l}\text { Age } \\
(y r s)\end{array}$} & \multirow[t]{2}{*}{$\begin{array}{l}\text { Birth- } \\
\text { place }\end{array}$} & \multirow[t]{2}{*}{$\begin{array}{l}\text { Sexual } \\
\text { polarity }\end{array}$} & \multicolumn{2}{|c|}{ Treatment given } & \multirow{2}{*}{ 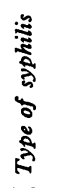 } & \multicolumn{2}{|c|}{ Serology } & \multirow{2}{*}{ 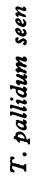 } & \multirow{2}{*}{ 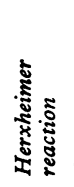 } & \multirow{2}{*}{ Comments } \\
\hline & & & & $\begin{array}{l}\text { Days } \\
\text { since }\end{array}$ & $\begin{array}{l}\text { Type } \\
\text { (m.u.) }\end{array}$ & & $W R$ & $V L R$ & & & \\
\hline $39 \star$ & 30 & UK & $\mathbf{M}$ & 150 & Pen $1 \cdot 2$ & $\mathbf{I}$ & $\frac{1}{32}$ & + & + & 0 & $\begin{array}{l}\text { Promiscuous homosexual previously treated for secondary } \\
\text { syphilis } 8 \text { mths before with negative serology } 3 \text { months later }\end{array}$ \\
\hline$\star 41^{\star}$ & 27 & UK & $\mathbf{M}$ & 63 & Pen 1.2 & $\mathbf{I}$ & $\frac{1}{16}$ & ++ & $\mathbf{0}$ & $\mathbf{0}$ & Numerous contacts since his gonorrhoea was treated \\
\hline $108^{\star}$ & 40 & Canada & $M$ & 147 & $?$ & II & $\frac{1}{40}$ & ++ & $\mathbf{0}$ & 0 & $\begin{array}{l}\text { Numerous contacts since his gonorrhoea was treated in } \\
\text { France }\end{array}$ \\
\hline$\star 119^{\star}$ & 28 & W.I. & F & 29 & Pen $1 \cdot 2$ & I & - & - & + & + & $\begin{array}{l}\text { Known contact with a case of secondary syphilis } 2 \text { wks } \\
\text { before chancre developed }\end{array}$ \\
\hline 125 & 40 & W.I. & $\mathbf{F}$ & 124 & Pen $1 \cdot 2$ & I & - & - & + & + & $\begin{array}{l}\text { Was given prophylactic treatment } 6 \text { mths before when } \\
\text { wife had primary syphilis. But had girl friend who } \\
\text { probably perpetuated the condition although she was } \\
\text { never seen by us }\end{array}$ \\
\hline$\star 157^{\star}$ & 24 & Brazil & $\left.\begin{array}{l}\mathbf{M} \\
\mathbf{F}\end{array}\right\}$ & 180 & $?$ & III & $\frac{1}{40}$ & + & 0 & 0 & $\begin{array}{l}2 \text { wks previously had been told all was well after a check } \\
\text { for V.D. in Stockholm. Admitted to numerous contacts, } \\
\text { mostly homosexual, since his gonorrhoea treated in } \\
\text { Brazil }\end{array}$ \\
\hline$\star 178$ & 30 & UK & M & 157 & Pen $1 \cdot 2$ & I & $\frac{1}{40}$ & + & 0 & 0 & $\begin{array}{l}\text { Denied any sexual contact in the } 5 \mathrm{mths} \text { since his } \\
\text { gonorrhoea was treated, but had negative serology } 1 \mathrm{mth} \\
\text { before diagnosis of syphilis was made }\end{array}$ \\
\hline$\star 198$ & 26 & UK & $\mathbf{M}$ & 65 & Pen 1.2 & I & - & +0 & + & + & Numerous contacts since his gonorrhoea was treated \\
\hline 199 & 45 & W.I. & $\mathbf{F}$ & 149 & Pen $1 \cdot 2$ & III & b & + & 0 & + & $\begin{array}{l}\text { Wife was treated for secondary syphilis } 8 \text { wks before } \\
\text { diagnosis of syphilis was made in this patient. He had } \\
\text { had intercourse with her between his original treatment } \\
\text { for gonorrhoea and her treatment for syphilis }\end{array}$ \\
\hline $206^{\star}$ & 16 & UK & $\mathbf{M}$ & 97 & Amp 1 & $\mathbf{I}$ & $\frac{1}{d 0}$ & + & + & + & Numerous contacts since his gonorrhoea was treated \\
\hline $235^{\star}$ & 22 & Austria & $M$ & 126 & Pen $1 \cdot 2$ & I & - & - & + & + & Numerous contacts since his gonorrhoea was treated \\
\hline $247^{\star}$ & 32 & UK & $\mathbf{M}$ & 101 & Amp 2 & III & $\frac{1}{40}$ & ++ & 0 & $\mathbf{0}$ & Numerous contacts since his gonorrhoea was treated \\
\hline$\star 272 \star$ & 39 & UK & $\mathbf{M}$ & 71 & Pen 1.2 & $\mathbf{I}$ & $\frac{1}{4 i}$ & ++ & $\mathbf{0}$ & 0 & $\begin{array}{l}\text { Numerous contacts since his gonorrhoea was treated } \\
\text { When diagnosed as having syphilis was } \\
\text { already under treatment with tetracycline } 250 \text { mg. four } \\
\text { times a day for non-specific proctitis. Examining doctor } \\
\text { considered that appearances justified a diagnosis of } \\
\text { primary syphilis despite failure to find } T \text {. pallidum on } \\
\text { dark field microscopy. In retrospect a diagnosis of early } \\
\text { latent syphilis must be considered as at least a possiblity }\end{array}$ \\
\hline $274^{\star}$ & 23 & W.I. & $\mathbf{M}$ & 162 & Pen $\mathbf{1} \cdot 2$ & II & $\frac{1}{40}$ & $+\quad+$ & 0 & 0 & Numerous contacts since his gonorrhoea was treated \\
\hline $\begin{array}{l}\text { Amp } 1 \\
\text { Amp } 2= \\
\text { W.I. }=\mathbb{W} \\
\text { *These }\end{array}$ & imary & $\begin{array}{l}\text { hilis } \\
\text { philis } \\
\text { is with }\end{array}$ & in the $f$ & year & nfection & & & & & & \\
\hline
\end{tabular}




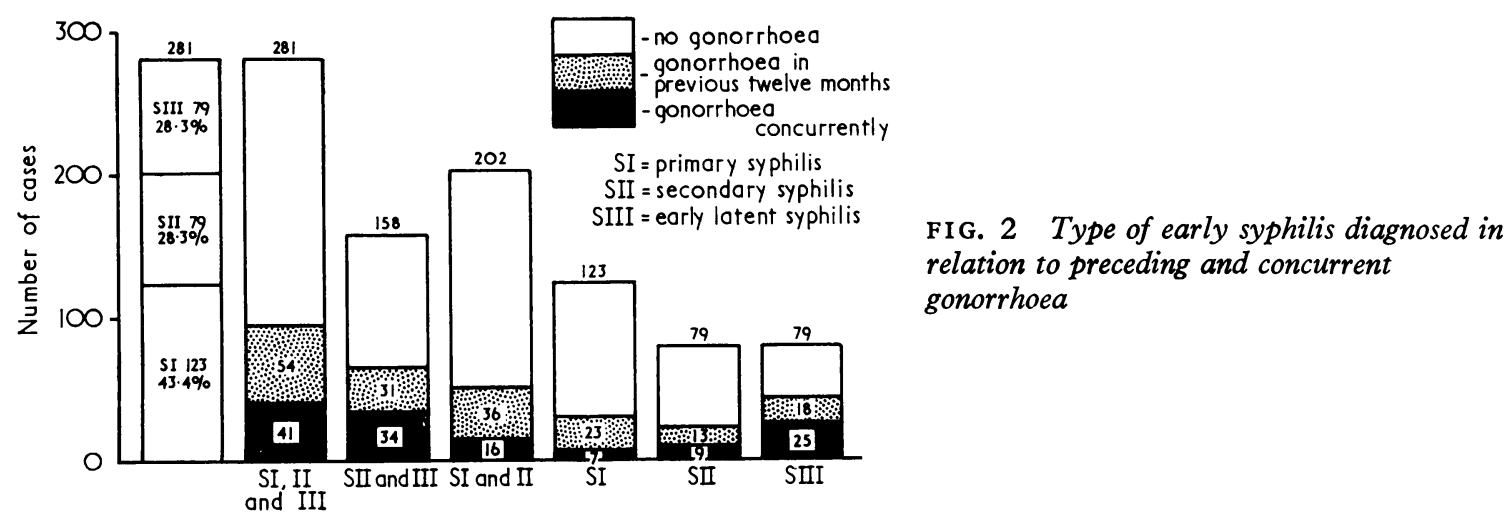

within 6 months of the original gonococcal infection.

Again the 'gonorrhoea net', with its differential effect according to the stage of syphilis involved, is clearly demonstrated. Fig. 2 shows that 25 out of 79 (31 per cent.) cases of early latent syphilis were diagnosed as a result of gonococcal infection compared with nine out of 79 (11 per cent.) cases of secondary syphilis and only seven out of $123(5 \cdot 8$ per cent.) cases of primary syphilis. Of the total 281 cases, 54 (19 per cent.) had had treatment for gonorrhoea in the previous 12 months. The same applied to eighteen out of 79 (22 per cent.) cases of early latent, thirteen out of 79 ( 16 per cent.) cases of secondary, and 23 out of 123 (19 per cent.) cases of primary syphilis. The conclusion seems to be that, whatever else may happen, the incidence of the different types of early syphilis is not substantially changed by the treatment of gonorrhoea.

Although not the primary concern of this study, the analysis provided some sociological interest. Fig. 3 shows a breakdown of the patients relating birth in the U.K. and sexual polarity. 182 of the 281

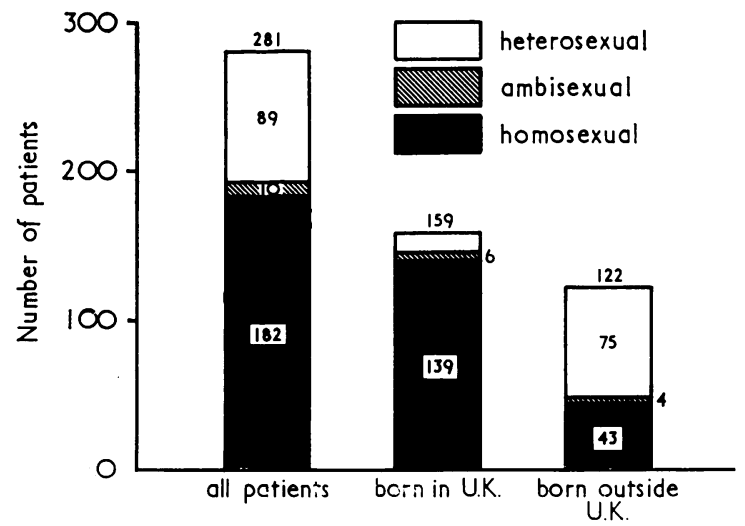

FIG. 3 Sexual polarity and birth in the U.K. of male patients with early syphilis
(65 per cent.) patients were exclusively homosexual and a further ten ( 3.5 per cent.) were ambisexual. 122 (40 per cent.) of the patients were not born in the U.K.; only fourteen ( 5 per cent.) patients were exclusively heterosexual and born in the U.K.

This total of 68.5 per cent. of patients with homosexual contacts is considerably higher than the figure of Nicol (1960) and King (1962), who recorded 32 and 14 per cent. respectively. However, Jefferiss (1962) found that 70 per cent. of early syphilis cases admitted homosexual exposure, and Mascall (1961) reported an incidence of 79 per cent. More recent figures from Jefferiss (1966) were slightly lower at 62 per cent.

\section{(b) Relating syphilis to gonorrhoea}

The main theme of the study is demonstrated in Fig. 4 which gives the incidence of early syphilis in patients with gonorrhoea concurrently and at 3month intervals in the previous 12 months.

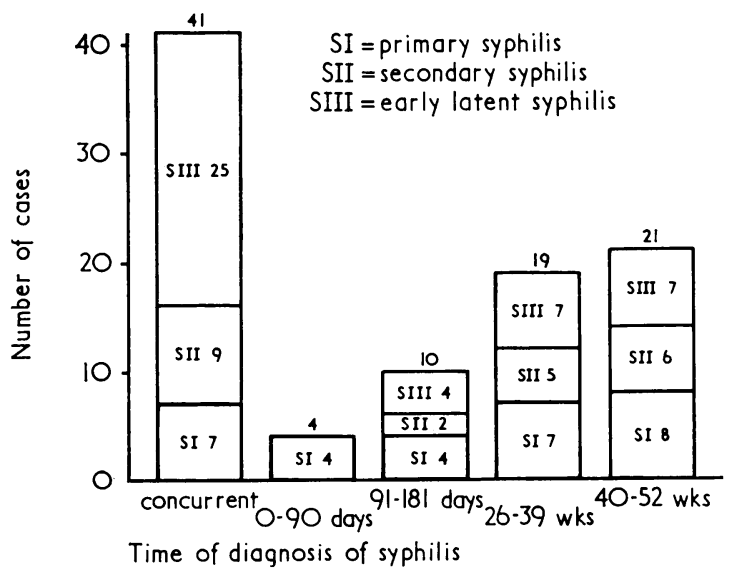

FIG. 4 Types of early syphilis related to gonorrhoea concurrently and at 3-month intervals in the previous 12 months 
The 'gonorrhoea net' has already been discussed and must immediately invalidate any conclusions based only on the total figures for the first 90 days. But it has been shown that the effect of the net on primary syphilis is not great, and the totals in Fig. 4 show that there was 50 per cent. less primary syphilis in the first 6 months than in the second 6 months after treatment of gonorrhoea. Possible explanations of this observation are:

(i) That it is an artefact caused by the low numbers involved. This explanation is supported by the fact that the decrease is spread evenly to include the second 3-month period; this period, being beyond the generally-accepted incubation time of syphilis, should not have been affected by the previous treatment for gonorrhoea.

(ii) That patients treated for gonorrhoea refrain from sexual intercourse for a considerable time afterwards, thereby reducing their chances of developing primary syphilis in the subsequent 6 months. Experience in venereology suggests that this explanation is unlikely.

(iii) That incubating syphilis is being masked for 3 to 6 months or more before manifesting itself. There is no evidence from the figures to support this but, if only a few cases were involved, they might have been absorbed by the other columns without noticeable effect.

(iv) That incubating syphilis is being 'accidentally' cured by the treatment for gonorrhoea. Some support for this possibility may be found below.

\section{(c) Discussing particular cases}

So far no consideration has been given to the probable effect on the figures obtained of infections acquired after the initial treatment for gonorrhoea. Table I shows that only with the three heterosexual patients (cases 119, 125, and 199-all West Indians) were any contacts seen by us, and in each of these cases it seemed likely that the syphilis had been caught subsequently. The same might apply to the ten out of eleven homosexual patients who admitted to numerous contacts since the original treatment; but since none of their consorts were knowingly seen by us there is no evidence to support or refute this possibility.

One patient (178) denied any contacts since his original treatment 5 months before; but his serological tests for syphilis had all been negative 1 month before. The conclusion must be either that he was not truthful or that his syphilis was masked for at least 4 months before passing quickly into a latent stage. Another patient (157) might represent a similar case, for, although he admitted to numerous contacts since his treatment for gonorrhoea 6 months before, he told us that he had been checked for venereal disease 2 weeks before, in Stockholm, and had been told all was well. These two cases raise the possibility that masked syphilis may remain in a sero-negative latent state for 4 to 6 months before becoming sero-positive without clinical manifestations. But figures from above have suggested that the treatment of gonorrhoea has little effect on the type of syphilis that subsequently develops, so it seems likely that both patients should be dismissed as unreliable historians.

Of the four patients who developed syphilis within the usually accepted period of 90 days, one (119) had had subsequent contact with a known case of secondary syphilis and developed his chancre 2 weeks later. The other three $(41,198$, and 272$)$ were diagnosed as having syphilis $67 \pm 5$ days after their gonorrhoea had been treated, and it may be that this clustering represents a common incubation period of masked syphilis; but as they all admitted numerous homosexual contacts in the intervening period, they could all have been infected subsequently. If they were infected after their gonorrhoea had been cured, then we have found no cases in which masked syphilis became manifest in the first 90 days. If, on the other hand, it is argued that these three patients provide evidence of masking, why did only one patient develop a new primary infection in the first 3 months compared with four to eight patients in each of the subsequent 3-month periods?

\section{(d) Conclusions}

Whatever the answer, the most striking feature of this study is that, despite the fact that approximately one in five of the patients with early syphilis had been treated for gonorrhoea in the previous 12 months, still only four cases are available with which to consider the 90-day follow-up time. Thus, a situation has emerged in which the failure to find evidence assumes a greater importance than the evidence actually found. If this principle were extended to the last 20 years, it might be considered that the lack of evidence on the subject of masking suggests either that syphilis is masked for so long that realization of the masking is obscured, or that incubating syphilis is not masked but aborted by the treatment of gonorrhoea. Until it is possible to discover the actual incidence of incubating syphilis in patients with gonorrhoea the conclusions must remain negative ones. No such information is at present available, but it could be obtained if a large number of cases of gonorrhoea were treated with non-treponemicidal drugs.

SERIES III: NINETY MALE CASES OF RECTAL GONORRHOEA Table II (overleaf) summarizes the (unpublished) 
TABLE II Summary of the findings in ninety male patients treated for rectal gonorrhoea with Septrin, 1 tablet twice daily for 5 days

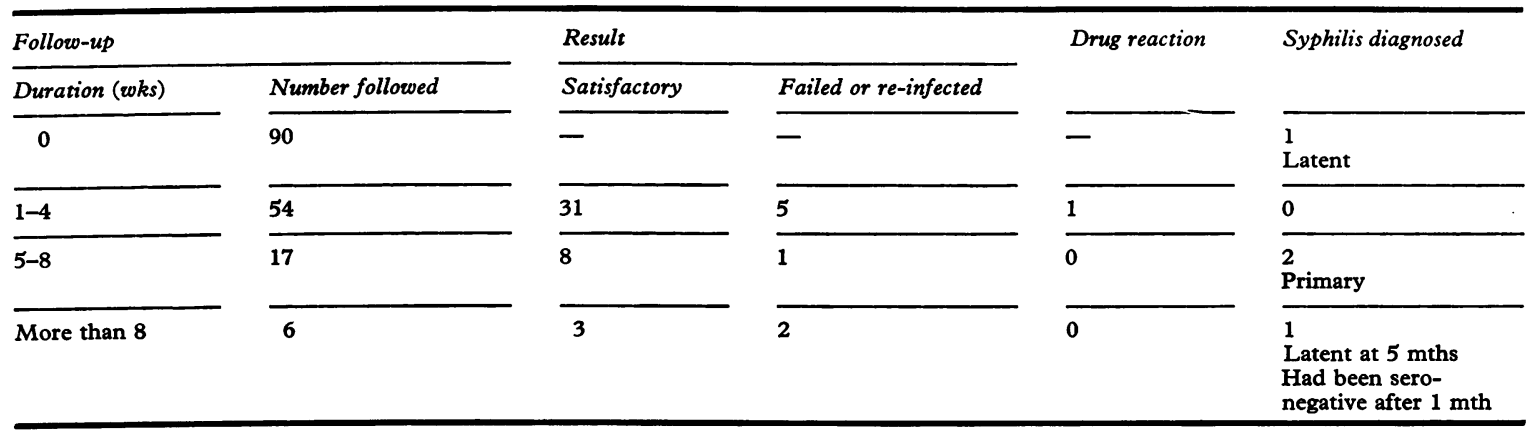

results obtained in this clinic when ninety homosexual patients with rectal gonorrhoea were treated with Septrin tablets, two twice daily for 5 days. Septrin, a combination of trimethoprim and sulphamethoxazole, has been reported by Jefferiss (1969) and Csonka (1969) to be non-treponemicidal.

Such a small series of patients at a high risk of contracting syphilis cannot be considered representative of the whole community; nevertheless only one patient was found to have syphilis at the time the gonorrhoea was diagnosed, which is just the incidence to be expected from the total clinic figures for 1968. Yet two cases of syphilis developed within the 90 days after treatment, an incidence of 2.2 per cent. This represents a greater than 30 -fold increase on the incidence of 0.06 per cent. obtained from the total clinic figures. It must be emphasized that the element of selection and the low numbers involved make these figures totally inadequate for any firm conclusions; yet they do suggest that cases of syphilis are either being cured or masked for longer than 90 days when treponemicidal drugs are used to treat gonorrhoea.

As to the choice between these two suggestions, it has been assumed, on theoretical grounds, that if incubating syphilis is not quite cured by the treatment of gonorrhoea-i.e. is masked-it should still show itself again within its normal maximum incubation period-i.e. 90 days. No evidence has been found to refute this logic and, when considering a subject on which 'no evidence' is often the only evidence, this must favour the possibility that incubating syphilis is usually cured and not masked by the treatment of gonorrhoea.

Although no firm conclusions can be reached as a result of the above studies, the following statements can be made:

(1) Of the patients with early latent syphilis involved in the study almost one-third became available for diagnosis because they subsequently caught gonorrhoea-the 'gonorrhoea net'.

(2) U.K.-born heterosexual patients comprised only 5 per cent. of the total of patients with early syphilis.

(3) Of 2,992 patients with gonorrhoea routinely treated with procaine penicillin 1.2 mega units, only two $(0.06$ per cent) were known to have developed evidence of syphilis in the subsequent 90 days.

(4) Having allowed for the 'gonorrhoea net', no evidence was found to suggest that the treatment of gonorrhoea had any influence on the stage of early syphilis subsequently diagnosed.

(5) No evidence was found to support the concept that incubating syphilis may be masked by the routine penicillin treatment of gonorrhoea and manifest itself within the subsequent 90 days.

(6) There were 50 per cent. fewer cases of primary syphilis in the first 6 months than in the second 6 months following treatment for gonorrhoea.

(7) In an unrepresentative series of 90 homosexual men treated for rectal gonorrhoea with a nontreponemicidal drug, the incidence of syphilis in the subsequent 90 days, two cases, was more than thirty times that in the unselected clinic patients; unfortunately the degree of selection and the small numbers involved do not permit any firm conclusions to be drawn.

Two steps are available which could elucidate the problems discussed:

(a) Separate notification of dual infections.

(b) A short-term, but national, use of non-treponemicidal drugs for the treatment of gonorrhoea.

The first should present no difficulty, yet it was first suggested by Leeming (1947) and has not, thus far, been implemented. The second might not, in the short term, be justified in view of the possible syphilis explosion it might produce. Whether, in the 
long term, we can afford to omit it, we shall discover in due course.

\section{Summary}

At St. Mary's Hospital, Paddington, an attempt was made to re-appraise the effect of treatment for gonorrhoea on incubating syphilis. Four approaches were used:

Observation of the subsequent development of syphilis among nearly 3,000 men treated for gonorrhoea with procaine penicillin 1.2 mega units;

Retrospective study of the history of treated gonorrhoea among 281 men with early syphilis;

Study of fourteen cases in which early syphilis presented within 6 months of treatment for gonorrhoea;

Observation of the development of syphilis in homosexual men treated for rectal gonorrhoea with a nontreponemicidal drug.

In the event, no proven conclusions could be arrived at for lack of sufficient evidence, despite the various approaches. The principal tentative conclusions were:

No evidence suggested that penicillin treatment of gonorrhoea influenced the type of early syphilis subsequently diagnosed;

50 per cent. fewer cases of primary syphilis occurred in the first 6 months than in the second 6 months after gonorrhoea treatment;

The small number of dual infections available for study and the lack of positive evidence favoured the belief that penicillin given for gonorrhoea is more likely to cure incubating syphilis than to mask it.

I am indebted to Dr. F. J. G. Jefferiss and Dr. R. R. Willcox for their encouragement and constructive criticism and for allowing me to study the case histories of their patients; and to Miss C. N. Reynolds for her help in preparing the text.

\section{References}

Allan, A. (1946) Brit. med. f., 1, 314

BAUER, T. J. (1949) f. vener. Dis. Inform., 30, 185

Canizares, O. (1944) Arch. Derm. Syph. (Chicago), 50, 246

Cronin, E. (1947) Brit. F. vener. Dis., 23, 15
CsonkA, G. W. (1969) Postgrad. med. F., 45, Suppl., p. 77 (Synergy of trimethoprim and sulphonamides)

JEFFERISS, F. J. G. (1962) Brit. med. $\mathcal{F} ., 1,1751$

- (1966) Brit. F. Vener. Dis., 42, 46

- (1969) Report to M.S.S.V.D., Budapest

KIng, A. J. (1962) Proc. roy. Soc. Med., 55, 869

Leeming, J. A. L. (1947) Brit. F. Vener. Dis., 23, 155

LYDON, F. L., and Cowe, W. R. S. (1945) Brit. med. F., 1,110

MACFARLANE, W. V. (1950) Brit. F. vener. Dis., 26, 69

Magnuson, H. J., and Eagle, H. (1945) Amer. F. Syph., 29, 587

Mahoney, J. F., ARnOld, R. C., and HarRis, A. (1943) F. vener. Dis. Inform., 24, 355

MASCALL, N. (1961) Brit. med. f., 1, 899

Nicol, C. (1960) Practitioner, 184, 345

WILlcox, R. R. (1950) Med. Wld (Lond.), 73, 89

Nouvelle estimation de l'influence du traitement de la gonococcie sur l'incubation de la syphilis

SOMMAIRE

A l'Hôpital St. Mary, Paddington, on a tenté d'étudier de nouveau l'effet du traitement de la gonococcie sur la syphilis en incubation. Ceci fut fait selon quatre approches: observation, chez presque 3.000 hommes traités par 1,2 m.u. de pénicilline procaïne pour gonococcie, de l'évolution des cas de syphilis pouvant survenir; étude rétrospective des anamnèses de traitement antigonococcique chez 281 hommes présentant une syphilis récente; étude de 14 cas chez lesquels une syphilis récente s'était développée moins de 6 mois après un traitement antigonococcique; observation de l'évolution de la syphilis chez des homosexuels masculins traités pour gonococcie rectale par un médicament non tréponémicide. Dans ces cas, on ne put arriver à aucune conclusion faute de preuves suffisantes, et malgré les différentes approches. Sous réserves, les principales conclusions furent: qu'il n'y a pas de preuves qui suggèrent que le traitement d'une gonococcie par la pénicilline ait une influence sur le type de syphilis récente ultérieurement diagnostiquée; que moins de 50 pour cent de cas de syphilis primaire survinrent dans les premiers six mois plutôt que dans les seconds six mois après la gonococcie; que le petit nombre disponible d'infections doubles étudiées et que l'absence de preuves positives soutient le point de vue que le pénicilline administrée pour une gonococcie est plus susceptible de traiter une syphilis en incubation que de la masquer. 